\title{
Un altfel de profil al misionarului creștin - Dag Hammarskjöld (1905-1961)
}

\author{
Maxim (Iuliu-Marius) MORARIU*
}

Abstract: A different profile of Christian Missionary - Dag Hammarskjöld (1905-1961). Governor of the National Bank of Sweden, second General Secretary of ONU, professor at the Uppsala University, Dag Hammarskjöld was a good diplomat and a good Christian too. He proposed a new way of seeing the Christian Mission and to practice the Christian Principles and he was, for that, classified between "the contemporary mystics". Unfortunately, in Romanian Theology, he is almost unknown. He's most important work of theology, Markings ${ }^{3}$, wasn't until now translated in Romanian language, and he's ideas are

\footnotetext{
* PhD candidate, Faculty of Orthodox Theology at University „Babeş-Bolyai", Cluj-Napoca, Romania.

${ }^{2}$ Karlmann Beyschlag, Dag Hammarsjkold, in Gerhard Ruchbach, Joseph Sudbrach (eds.) „Grandi misciti dal 300 al 1900”, Bologna, Edizioni Dehoniane Bologna, 2003, p. 509.

${ }^{3}$ The princeps edition appeared in 1963, but we had acces only at one English version. See: Dag Hammarskjöld, Markings, London, Faber and Faber, 1972.
} 


\title{
Maxim (Iuliu-Marius) MORARIU
}

almost unknown in Orthodox Theology ${ }^{4}$. That is the reason for what, the author of this research, which contributed at the dissemination of his ideas ${ }^{5}$, written this study. In its pages, is analysed the way how see our author the profile of a Christian Missionary and there are presented the main qualities of the Christian Missionary, us are they seen by the Swedish diplomat. The research is based on his works and on the articles and studies about his life and activity. The work it will be a new approach in Romanian Literature and it we hope it will be the start of the discovering Dag Hammarskjöld in Romanian Theology.

Keywords: neutrality, pragmatism, economy, law, ONU.

\section{Introducere}

Diplomatul suedez Dag Hammarsjkold (1905-1961), cunoscut

\begin{abstract}
${ }^{4}$ That is why, the little article of Valentin Vesa, is almost a new approach in Romanian Theological literature. See: Valentin Vesa, Dag Hammarsjkold- om politic şi mistic al credinţei, în „Renaşterea”, Serie nouă, anul XXV, nr. 12 (296), Decembrie, Cluj-Napoca, 2014, p. 5.

${ }^{5} \mathrm{He}$ published the study entitled: Iuliu-Marius Morariu, Interferenţa dintre teologie, etică, economie şi politică în viaţa şi activitatea lui Dag Hammarskjold (1905-1961), în Georgiana Iuliana Spineanu, Maria Semen, (eds.) Sententiasesiune internaţională de comunicări ştiințifice studențeşti, volum de lucrăriediţia a V-a, 4-6 Decembrie 2014, Târgu Jiu, Târgu Jiu, Editura Academica Brâncuşi, 2014, p. 371-376; Idem, The relation between religion and politics in the work of the diplomat Dag Hammarskjöld (1905-1961), în „Research and Science Today, Supplement No. 3/2015”, Târgu Jiu, 2015, pp. 280-283, and sustained the conferences: „Interferenţa dintre teologie, etică, economie şi politică în viaţa şi activitatea lui Dag Hammarskjold (1905-1961)", at Sentenţia - sesiune internaţională de comunicări ştiinţifice studenţeşti, ediţia a V-a, Târgu Jiu, 4-6.12. 2014 and The relation between religion and politicts in the work of the diplomat Dag Hammarskjöld (1905-1961), at VIII International Student Conference "Politics \& Society in Central and Eastern Europe", Wrocław, 21. 05. 2015.
\end{abstract}


mediului teologic apusean ${ }^{6}$ şi celui protestant ${ }^{7}$, şi cercetat deopotrivă şi de către autorii preocupaţi de istoria contemporană şi de evoluţia relaţiilor internaţionale, este, din nefericire, aproape necunoscut mediului teologic românesc, în ciuda ideilor sale relevante şi, nu suficient de familiar mediului laic. De aceea, acest studiu îşi propune ca, pe baza bibliografiei investigate, să îl aducă în atenţia mediului ştiinţific românesc, valorificând cu precădere modalitătile prin care el a fost un adevărat misionar al creștinismului în spaţiul politic, economic şi diplomatic în care a activat.

În cadrul cercetării, vom realiza de asemenea o scurtă prezentare bio-bibliografică, atât datorită faptului că, pentru a defini prin prisma trăsăturilor lui fundamentale, profilul misionar al unui om, e necesar ca, în partea introductivă a demersului să se regăsească o prezentare, fie şi succintă, a biografiei şi a operei lui, în care să se reflecte principalele trăsături în acest sens, cât şi din pricina faptului că, aşa cum am menţionat deja, multor cititori le este necunoscut personajul investigat, iar biografia lui îi va familiariza cu el. Pe de altă parte, cunoaşterea mediului în care s-a format şi a activat el şi a familiei lui, ilustrează (dacă ne raportăm la faptul că bunicul său, Almguist ${ }^{8}$, a fost considerat unul dintre cei mai mari poeţi suedezi, iar tatăl său a fost directorul fundaţiei Nobel ${ }^{9}$ ), felul în care s-a amprentat

${ }^{6}$ Cf. Peter Dinzelbacher (ed.), Dictionnaire de la Mystique, Brepols, Alfred Kroner Verlag, 1993, p. 82-85, p. 366.

${ }^{7}$ Cf. Alina J. Lyonn, Moral motives and Policy actions. The case of Dag Hammarsjkold at the Unived Nations, în „Public Integrity”, vol. 9, no. 1, Winter, 2006, p. 79-95; Allan D. Falconer, ,In this Sacrament the Whole of What Our Religion Mean is expressed”, în „Theology in Scotland”, vol. XV, nr. 2, 2008, p. 21-34; Bernard Erling, Dag Hammarsjkold's use of Thomas a Kemphis, in „Lutheran Quarterly”, year I, 1987, p. 341-357.

${ }^{8}$ Bernd Jordan, Alexander Lenz, 100 de personalităţi ale secolului- politicieni, trad. Dragoş Dinulescu, Bucureşti, Editura All Educaţional, 2002, p. 80.

$9 * * *$, The new Encyclopaedia Britannica, vol. V, XVth Edition, Chicago, Encyclopaedia Britannica Inc, 1991, p. 664; ***, Grand Larousse encyclopedique en dix volumes, Tome cinquieme, Paris, Librarie Larousse, 1962, p. 769; ***, Encyclopaedia Britannica, vol. 11, Chicago, London, Toronto, Geneva, 
educaţia primită în familie asupra lui.

Fără a avea pretenţia unei biografii exhaustive cum este cea a lui Roger Lipsy ${ }^{10}$ (care însă nu abordează latura lui teologică decât într-o manieră de-a dreptul pasageră), vom încerca totuşi să realizăm prezentarea propusă folosindu-ne atât de operele autorului ${ }^{11}$, cât şi de istoriografia existentă, furnizată în mare măsură de către fundaţia ce poartă numele personajului ${ }^{12}$.

\section{Dag Hammarsjkold - scurtă incursiune biografică}

Diplomatul, economistul, politicianul şi filosoful Dag Hammarsjkold s-a născut la data de 29 iulie 1905 în localitatea Jonkoping. A fost fiul lui Hjalman Hammarskjöld, prim ministru al Suediei (1914-1917) şi director al Fundaţiei Premiilor Nobel (19241927) ${ }^{13}$ şi nepot al poetului suedez Carl Jonas Love Almquist (17931866) $)^{14}$, reprezentant al romantismului suedez. ${ }^{15}$.

Funcţia politică deţinută de tatăl său îl va face să iş̧i petreacă cea mai mare parte a copilăriei sale la Uppsala ${ }^{16}$, oraş cu care va interfera

Encyclopaedia Britannica, inc., 1962, p. 131-132.

${ }^{10}$ Roger Lipsy, Hammarsjkold - a life, Michigan, University of Michigan Press, 2013.

${ }^{11}$ Dag Hammarskjöld, Markings; Gunnel Toren (ed.), Literature (On the 50th Anniversary of his Death), Dag Uppsala,Hammarskjöld Library, 2011.

${ }^{12} \mathrm{Al}$ cărei site oficial este: http://www.dhf.uu.se/, accesat 01. 07. 2015. Aici se găsesc materiale importante legate de viaţa şi activitatea lui.

$13 * * *$, The new Encyclopaedia Britannica, p. 664.

${ }^{14}$ Vezi: ***, Encyclopaedia Britannica, vol. 1, Chicago, London, Toronto, Geneva, Encyclopaedia Britannica INC, 1962, p. 674; John Viklund, Persuasion in Ninetenth-Century Sweedish Fiction: C. J. L Almquist and the ,Rethorical situation", în Paernile Harsting and John Viklund (eds.), ,Retoric and Literature in Finland and Sweden 1600-1900", Copenhaga, Nordisk Nedvaek for Retorikkens Historie, 2008, pp. 1-23, pentru mai multe informaţii privitoare la biografia lui şi la elementele caracteristice ale scrisului său literar.

${ }^{15}$ Bernd Jordan, Alexander Lenz, op. cit.,. 80.

${ }^{16}$ Valentin Vesa, ar. cit., p. 5. 
destul de mult de-a lungul vieţii sale. De altfel, de capitala suedeză se leagă şi prima parte a formării sale ca intelectual căci, aici a obţinut licenţa în filosofie şi masteratul în Drept. Cu toate acestea, doctoratul său nu va avea în centru nici una dintre aceste specializări, căci, în anul 1934, va obţine titlul de doctor în economie la Amsterdam ${ }^{17}$.

În acest domeniu va şi activa o vreme căci, după ce, între anii 1930-1933, a fost numit secretar într-o comisie guvernamentală, a devenit secretar şi apoi guvernator al Băncii naţionale a Suediei, cea din urmă funcţie deţinându-o între anii 1941-1948. Începând cu anul 1947, a intrat în Ministerul Afacerilor Externe, iar din anul 1954 a devenit cel de-al doilea secretar general al ONU, funcţie pe care o va deţine până la decesul survenit în condiţii încă neelucidate, în urma unui accident aviatic, în timp ce se deplasa înspre Congo, cu scopul de a media criza de acolo ${ }^{18}$.

Din această postură, el a participat în calitate de mediator la soluţionarea unor probleme importante precum criza Suezului $(1956)^{19}$, cea a Libanului (1958) şi la cea congoleză, încercând totodată să asigure egalitatea în drepturi a statelor mici cu cele mari, în cadrul organizaţiei, şi criticând orice formă de dictatură, fapt ce i-a adus adesea conflicte cu oameni politici precum Hruşciov.

${ }^{17}$ Karlmann Beyschlag, ar. cit.,p. 510.

${ }^{18}$ Cf. Bernd Jordan, Alexander Lenz, op. cit., p. 80-81; ***, The new Encyclopaedia Britannica, p. 664-665; ***, Enciclopedia de istorie universală, trad. Alexandru Balaci, Mădălina Chelemen, Radu Gâdei, Sorina Venier, Bucureşti, Editura All Educaţional, 2003, p. 694; Thomas Parish, Encyclopedia Războiului Rece, trad. Ion Nastasia, Bucureşti, Editura Univers Enciclopedic, 2002, p. 130.

${ }^{19}$ Cf. Gheorghe Văduva, Mihai-Ştefan Dinu, Crizele politico-militare ale inceputului de mileniu, Bucureşti, Editura Universităţii Naţionale de Apărare, 2005, p. 26; Andre Siegfried, Suez, Panama: et les routes maritimes mondiales, avec 33 cartes et graphiques, Nouvelle édition revue et augmentée, Paris, Armand Collin, 1948, şi Wiliam Roger Luis, Owen Roger, Suez 1956: the crisis and its consequences, Oxford, Oxford University Press, 1991, pentru mai multe informaţii cu privire la acest subiect. 
Ca orator, nu era unul dintre cei mai apreciaţi, fapt cauzat probabil şi de necesitatea prezentării în limba engleză a discursurilor. Această lacună îi va aduce chiar şi critici postume. Un cercetător preocupat de discursurile lui le caracterizează astfel:

„Discursurile sale nu erau în mod special carismatice, ca cele ale predecesorului său, Trygve Lie, şi îşi citea adesea discursurile pe care el însuşi le scrisese, într-o manieră monotonă" ${ }^{\prime 20}$.

În ciuda acestui fapt, el a reuşit totuşi să se exprime cu competenţă asupra unor probleme importante şi să îşi impună punctul de vedere. Astfel, dacă atunci când a devenit secretar al instituţiei pomenite, funcţia sa avea mai mult o valoare simbolică, la decesul său, rolul ei în cadrul structurii din care făcea parte crescuse considerabil ${ }^{21}$.

Decesul său a survenit, după cum am pomenit deja, într-un accident aviatic, în data de 18 septembrie a anului 1961, în timp ce se deplasa spre Congo, în scopul soluţionării crizei de aici. Cauzele accidentului aviatic, care i-au pus capăt zilelor, nu au fost nici astăzi elucidate, unii simpatizanţi ai săi considerând până astăzi că a fost vorba despre un atentat.

Pentru meritele sale, diplomatul suedez a devenit cel de-al doilea om istorie care a primit postum Premiul Nobel pentru pace ${ }^{22}$.

${ }^{20}$ Stålne, Kristian, The Meaning-making of Dag Hammarskjöld, în „Integral Review", vol. 7, Nr. 2/2011, p. 138.

${ }^{21}$ „În aprilie 1953, Dag Hammarskjold (1905-1961) a fost ales Secretar General al Organizaţiei Naţiunilor Unite, poziţie pe care a deţinut-o pentru opt ani. I s-a spus de către predecesorul lui că era pe cale ,„s̆ intre în cea mai imposibilă slujbă de pe acest pământ". Dar, datorită integrităţii sale personale, curajului, abilităţilor diplomatice, şi entuziasmul său în implementarea Cartei Naţiunilor unite, Hammarskjold a adus o nouă autoritate acestui rol. Abordarea sa inovativă a întărit abilitatea ONU de a evita iminența conflictelor. În secolul XX, Hammarskjold a fost suedezul care a devenit foarte bine cunoscut pentru cunoştinţele sale internaţionale". Gunel Torren, Dag Hammarskjold- the Pacemaker, în Gunnel Toren (ed.), ,Dag Hammarskjold, Literature (On the 50th Anniversary of his Death)", Uppsala, Dag Hammarskjöld Library, 2011, p. 5. ${ }^{22}$ Valentin Vesa, ar. cit., p. 5; Bernd Jordan, Alexander Lenz, op. cit., p. 80-81; 


\section{Un altfel de profil al Misionarului Creştin - Dag Hammarskjöld (1905-1961)}

Dag Hammarsjkold e departe de tot ceea ce ar putea însemna, în accepţiunea clasică a termenului, misionarul. Departe de a fi un prozelit zelos care să încerce să propovăduiască şi altora crezurile sale şi să îi determine să le aplice şi ei, protestantul Dag era un om cu trăire sinceră, care nu se sfia să vorbească despre crezurile sale, dar care nu ţinea să epateze prin ele. $\mathrm{Cu}$ toate acestea, el este totuşi un misionar atât prin faptul că a fost un creştin practicant, cât şi prin trăirile mistice pe care le-a avut şi pe care le-au deconspirat cugetările de-a dreptul patericale ${ }^{23}$ din Markings $^{24}$, tot ceea ce a făcut el fiind parte a unei mari strategii misionare, specială prin prisma particularităților ei, prin care se dorea propovăduirea lui Hristos şi se propuneau ca alternativă de viaţă bună principiile creştine.

Pus în situaţia de a participa la o serie de conferinţe ecumenice, el şi-a propovăduit crezurile lui, însă, pentru acest lucru nu ar putea fi considerat nici misionar, nici prozelit. $\mathrm{Cu}$ toate acestea, prin faptul că, uneori, în cadrul discursurilor pe care le rostea, fie în plenul ONU, fie în cadrul a diferite reuniuni ale acestei instituţii, dintre care o parte s-au păstrat şi astăzi ${ }^{25}$, se folosea cu încredere şi dibăcie fie de pasaje scripturistice, fie de citate din Sfinţii Părinţi, s-a dovedit un propovăduitor al principiilor creştine într-un mediu în care puţini s-au străduit să fie astfel şi unde astăzi acest lucru ar fi aproape imposibil.

Apoi, prin faptul că a dus o viaţă morală de o curăţie ireproşabilă,

***, The new Encyclopaedia Britannica, op. cit., p- 664-665; ***, Enciclopedia de istorie universală, p. 694; Thomas Parish, op. cit., p. 130; Karlmann Beyschlag, ar. cit., p. 510.

${ }^{23}$ Ibidem, p. 515.

${ }^{24}$ Dag Hammarsjkold, Markings. Traducerea care ar reda cel mai fidel sensul operei sale postume ar fi, după părerea nostră acela de Cugetări, mai degrabă decât cel de Marcaje, aşa cum propune Valentin Vesa, deşi nici acesta nu poate fi considerat eronat. Cf. Valentin Vesa, ar. cit. p. 5; Bernhard Erling, A Reader's Guide to Dag Hammarskjöld's Waymarks", Minnesota, St. Peter Press, 2010.

${ }^{25} \mathrm{Cf}$. http://www.youtube.com/watch?v=xEQr_dbH79Q\&hd=1, accesat 01. 07.2015. 
care i-a conferit şi un prestigiu aparte în rândul membrilor organizaţiei pe care o reprezenta ca diplomat, s-a dovedit din nou a fi un misionar. E greu de cuantificat efectul pe care 1-a avut curăţia şi corectitudinea vieţii sale asupra celor care 1-au cunoscut, însă e de presupus că unii dintre ei vor fi remarcat acest lucru şi îl vor fi ales drept model

Desigur, prin opera sa Markings, el a făcut postum o activitate misionară pe care nu şi-ar fi imaginat-o. Cugetările autobiografice de aici ${ }^{26}$, peste 250 la număr ${ }^{27}$, similare adesea celor din Pateric $^{28}$, îl relevă ca pe un om cu ample trăiri mistice, iar gândurile lui, de profunzime teologică, îl fac să fie clasificat de unii autori apuseni între ,marii mistici ai secolului XX" ${ }^{29}$. Caracterizând din perspectiva conţinutului această operă importantă, dar insuficient cunoscută în spaţiul teologic românesc, teologul Valentin Vesa (azi părintele Benedict) spunea:

„Jurnalul său spiritual exprimă trei idei majore despre viaţa sa interioară. Mai întâi, îl revelează ca o persoană pregătită să-i răspundă afirmativ oricui, când vine vorba despre sensul vieţii (interpretarea personală a 2 Cor. 11,19 ,În Hristos rezidă acel da). Cel de-al doilea element se referă la curajul vieţii, al itinerariului zilnic pas cu pas, cu ineditul și banalul său, dar, mai ales, cu aventura spirituală pe care ne-o propune. Și, în sfârșit, chemarea pătimirii în exigenţa unei smeriri absolute, care exprimă singurul mod de slăvire al omului" "30.

Ceea ce particularizează însă viziunea lui asupra credinţei, este modul pragmatic de raportare la creştinism şi la principiile lui.

\footnotetext{
${ }^{26}$ Peter Dinzelbacher, op. cit., p. 82-85, p. 366.

${ }^{27}$ Karlmann Beyschlag, ar. cit., p. 515.

${ }^{28}$ Este vorba despre Patericul egiptean; comparaţia îi aparţine autorului mai sus citat. Cf. ***, Patericul egiptean, ed. Petru Pleşa, Alba-Iulia, Editura Arhiepiscopiei Ortodoxe Române, 1999.

${ }^{29}$ Karlmann Beyschlag, ar. cit., p. 509. Alţii, la rândul lor, includ Markings, opera lui fundamentală, între marile scrieri autobiografice cu conţinut mistic din toate timpurile, alături de Confesiunile lui Augustin şi de alte lucrări similare. A se vedea, de exemplu: Peter Dinzelbacher, op. cit. ,p. 82-85, p. 366.

${ }^{30}$ Valentin Vesa, ar. cit., p. 5. Cf. Karlmann Beyschlag, ar. cit., p. 509.
} 
Etica globală, propovăduită de el, presupunea inovarea discursului politic cu dimensiunea spirituală a celuilalt ${ }^{31}$. Hammarsjkold chema la activism şi la trăirea creştinismului în spaţiul de activitate a fiecărui om. Altfel spus, el propunea ca fiecare om să trăiască, în modul lui de viaţă specific şi în cadrele în care se găsea în modul cel mai firesc şi plenar credinţa creştină.

Prin ceea ce a făcut el, prin ideile pe care le-a propovăduit şi prin felul în care a interacţionat cu cei din jur, personajul prezentat a fost astfel un misionar creştin, însă, unul atipic, ,un altfel de misionar", care nu a făcut din propovăduirea creştinismului un ţel, ci s-a străduit să îl ipostazieze în viaţa lui, misiunea devenind astfel o extensie a propriei lui persoane.

\section{Concluzii}

După cum am arătat şi anterior în paginile prezentării noastre, Dag Hammaarsjkold a fost un om educat în spirit creştin, un evanghelic practicant, care s-a străduit să-şi trăiască credinţ̧a aşa cum a ştiut mai bine şi a încercat să cultive o relaţie cu divinitatea. Prin trăirea sinceră a adevărurilor fundamentale de credinţă şi prin fundamentarea scripturistică şi patristică a opiniilor lui, la fel ca şi prin celelalte elemente care i-au impregnat biografie şi care, adesea într-o manieră subtilă şi greu observabilă, au interferat cu spaţiul

31 ,În această poziţie, Hammarskjőld a fost chemat să promoveze o etică globală, în cazul său, generată de experienţa sa mistică, pe care o definește: ,întotdeauna aici și acum - în acea libertate care presupune o distanţă, în acea tăcere născută din liniștire. Aceasta este libertatea în mijlocul acţiunii, o liniștire în mijlocul celorlalţi... În lumea noastră, calea sfinţeniei trece în mod obligatoriu prin spaţiul acţiunii”. Metodologia pe care o promovează Hammarskjőld vizează inovarea discursului politic cu dimensiunea spirituală a Celuilalt și a importanţei cunoașterii de sine. Și de aici, misiunea sa este limpede - ,a servi, ca un slujitor civil internaţional... activ ca un instrument, un catalizator, sau cel care inspiră". Valentin Vesa, ar. cit., p. 5; Cf. Dag Hammarsjkold, Markings, p. 270. 
religios, el a reuşit totuşi să propovăduiască şi altora, chiar dacă indirect, creştinismul, fiind, prin aceasta, un altfel de misionar creştin, unul care nu a propovăduit un ideal confesional ci un bine comun, fundamentat pe principii metafizice.

\section{References:}

1. Beyschlag, Karlmann, Dag Hammarsjkold, in Gerhard Ruchbach, Joseph Sudbrach (eds.), "Grandi misciti dal 300 al 1900", eds. Bologna, Edizioni Dehoniane Bologna, Bologna, 2003.

2. Dinzelbacher, Peter (ed.), Dictionnaire de la Mystique, Brepols, Alfred Kroner Verlag, 1993.

3. ***, Encyclopaedia Britannica, vol. 1, Chicago, London, Toronto, Geneva, Encyclopaedia Britannica INC, 1962.

4. ***, Encyclopaedia Britannica, vol. 11, Chicago, London, Toronto, Geneva, Encyclopaedia Britannica, inc., 1962.

5. ***, Enciclopedia de istorie universală, trad. Alexandru Balaci, Mădălina Chelemen, Radu Gâdei, Sorina Venier, Bucureşti, Editura All Educaţional, 2003.

6. Erling, Bernhard, A Reader's Guide to Dag Hammarskjöld's Waymarks", Minnesota, St. Peter Press, 2010.

7. Idem, Dag Hammarsjkold's use of Thomas a Kemphis, în „Lutheran Quarterly", year I, 1987.

8. Falconer, Allan D., "In this Sacrament the Whole of What Our Religion Mean is expressed”, în „Theology in Scotland”, vol. XV, nr. 2, 2008.

9. ***, Grand Larousse encyclopedique en dix volumes, Tome cinquieme, Paris, Librarie Larousse, 1962, p. 769.

10. Hammarskjöld, Dag, Literature (On the 50th Anniversary of his Death), ed. Gunnel Toren, Dag Uppsala,Hammarskjöld Library, 2011.

11. Idem, Markings, Faber and Faber, London, 1972.

12. Jordan, Bernd, Lenz, Alexander, 100 de personalităţi ale secoluluipoliticieni, trad. Dragoş Dinulescu, Bucureşti, Editura All Educaţional, 2002.

13. Lipsy, Roger, Hammarsjkold - a life, Michigan, University of Michigan Press, 2013.

14. Lyonn, Alina J., Moral motives and Policy actions. The case of Dag Hammarsjkold at the Unived Nations, în "Public Integrity", vol. 9, 
no. 1, Winter, 2006.

15. Morariu, Iuliu-Marius, Interferenţa dintre teologie, etică, economie şi politică în viaţa şi activitatea lui Dag Hammarskjold (19051961), Georgiana Iuliana Spineanu, Maria Semen (eds.), „Sentenţia - sesiune internaţională de comunicări ştiinţifice studenţeşti, volum de lucrări- ediţia a V-a, 4-6 Decembrie 2014, Târgu Jiu", Târgu Jiu, Editura Academica Brâncuşi, 2014.

16. Parish, Thomas, Enciclopedia Războiului Rece, trad. Ion Nastasia, Bucureşti, Editura Univers Enciclopedic, 2002.

17. ***, Patericul egiptean, ed. Petru Pleşa, Alba-Iulia, Editura Arhiepiscopiei Ortodoxe Române, 1999.

18. Roger, Luis Wiliam, Roger, Owen, Suez 1956: the crisis and its consequences, Oxford, Oxford University Press, 1991.

19. Siegfried, Andre, Suez, Panama: et les routes maritimes mondiales, avec 33 cartes et graphiques, Nouvelle édition revue et augmentée, Paris, Armand Collin, 1948.

20. Stålne, Kristian, The Meaning-making of Dag Hammarskjöld, în „Integral Review”, vol. 7, Nr. 2/2011.

21. ***, The new Encyclopaedia Britannica, vol. V, XVth Edition, Chicago, Encyclopaedia Britannica Inc, 1991.

22. Torren, Gunel, Dag Hammarskjold- the Pacemaker, în Gunnel Toren (ed.), "Dag Hammarskjold, Literature (On the 50th Anniversary of his Death)", Uppsala, Dag Hammarskjöld Library, 2011.

23. Văduva, Gheorghe, Dinu, Mihai-Ştefan, Crizele politico-militare ale inceputului de mileniu, Bucureşti, Editura Universităţii Naţionale de Apărare, 2005.

24. Vesa, Valentin Dag Hammarsjkold - om politic şi mistic al credinţei, în "Renaşterea", Serie nouă, anul XXV, nr. 12 (296), Decembrie, 2014.

25. Viklund, John, Persuasion in Ninetenth-Century Sweedish Fiction: C. J. L Almquist and the "Rethorical situation", în Paernile Harsting and John Viklund (eds.), "Retoric and Literature in Finland and Sweden 1600-1900", ed. Copenhaga, Nordisk Nedvaek for Retorikkens Historie, 2008.

26. http://www.dhf.uu.se/, accesat 01. 07. 2015.

27. http://www.youtube.com/watch?v=xEQr_dbH79Q\&hd=1, accesat 01. 07. 2015. 
